\title{
Impact of Endometriosis on Life-Course Potential: A Narrative Review
}

\author{
Stacey A Missmer' \\ Frank F Tu ${ }^{2}$ \\ Sanjay K Agarwal (iD ${ }^{3}$ \\ Charles Chapron ${ }^{4}$ \\ Ahmed M Soliman ${ }^{5}$ \\ Stephanie Chiuve ${ }^{5}$ \\ Samantha Eichner ${ }^{5}$ \\ Idhaliz Flores-Caldera (iD) ${ }^{6}$ \\ Andrew W Horne ${ }^{7}$ \\ Alexandra B Kimball ${ }^{8}$ \\ Marc R Laufer iD ${ }^{9}$ \\ Nicholas Leyland (D) 10 \\ Sukhbir S Singh iD ${ }^{\prime \prime}$ \\ Hugh S Taylor iD ${ }^{12}$ \\ Sawsan As-Sanie ${ }^{13}$ \\ 'Department of Obstetrics, Gynecology, and Reproductive \\ Biology, Michigan State University, Grand Rapids, MI, USA: \\ ${ }^{2}$ Department of Obstetrics and Gynecology, NorthShore \\ University Health System, Evanston, IL, USA; ${ }^{3}$ Department \\ of Reproductive Medicine, Center for Endometriosis \\ Research and Treatment, University of California San \\ Diego, La Jolla, CA, USA; ${ }^{4}$ Department of Gynecology \\ Obstetrics II and Reproductive Medicine, Université Paris \\ Descartes, Sorbonne Paris Cité, Faculté de Médecine, \\ Assistance Publique - Hôpitaux de Paris, Hôpital \\ Assistance Publique - Hôpitaux de Paris, Hôpital
Universitaire Paris Centre, Centre Hospitalier Universitair \\ Cochin, Paris, France; ${ }^{5} \mathrm{AbbVie}$ Inc., North Chicago, IL, \\ USA; ${ }^{6}$ Department of Obstetrics and Gynecology, Ponce \\ Health Sciences University - Ponce Research Institute, \\ School of Medicine, Ponce, Puerto Rico; ${ }^{7}$ Department of \\ Gynaecology and Reproductive Sciences, MRC Centre for \\ Reproductive Helth, University of Edinburgh, Edinburgh \\ Reproductive Health, University of Edinburgh, Edinbu \\ Acal Faculty Physicians, Beth Israe \\ Deaconess Medical Center, Boston, MA, USA; \\ 'Department of Obstetrics, Gynecology, and Reproductive \\ Biology, Boston Center for Endometriosis and Boston \\ Children's Hospital and Brigham and Women's Hospital, \\ Boston, MA, USA; ${ }^{10}$ Department of Obstetrics and \\ Gynaecology, McMaster University, Hamilton, Ontario, \\ Cynaecol "gy, McMaster Unity, Hamilton, Ontario, \\ Canida, "Department of Obstetrics and Gynecology, \\ University of Ottawa, and Ottawa Hospital Research \\ Institute, Ottawa, Ontario, Canada; ${ }^{12}$ Department of \\ Obstetrics, Gynecology and Reproductive Sciences, Yale \\ School of Medicine, New Haven, CT, USA; ${ }^{13}$ Department \\ of Obstetrics and Gynecology, University of Michigan \\ Health System, Ann Arbor, MI, USA
}

Correspondence: Stacey A Missmer College of Human Medicine, Michigan State University, I5 Michigan Street Northeast, Grand Rapids, MI 49503, USA $\mathrm{Tel}+$ I 6162342705

Email missmers@msu.edu
This article was published in the following Dove Press journal:

International Journal of General Medicine

\begin{abstract}
Endometriosis may exert a profound negative influence on the lives of individuals with the disorder, adversely affecting quality of life, participation in daily and social activities, physical and sexual functioning, relationships, educational and work productivity, mental health, and well-being. Over the course of a lifetime, these daily challenges may translate into limitations in achieving life goals such as pursuing or completing educational opportunities; making career choices or advancing in a chosen career; forming stable, fulfilling relationships; or starting a family, all of which ultimately alter one's life trajectory. The potential for endometriosis to impact the life course is considerable, as symptom onset generally occurs at a time of life (menarche through menopause, adolescence through middle age) when multiple life-changing and trajectory-defining decisions are made. Using a lifecourse approach, we examine how the known effects of endometriosis on life-domain satisfaction may impact health and well-being across the life course of affected individuals. We provide a quasi-systematic, narrative review of the literature as well as expert opinion on recommendations for clinical management and future research directions.
\end{abstract}

Keywords: endometriosis, health trajectory, life-course impairment

\section{The Value of a Life-Course Impact Approach}

Across healthcare fields and disease states, there has long been a recognition that exposures, or risk factors, over a lifetime-be they discrete, periodic, or ongoing-influence later outcomes, including health, well-being, and disease. The lifecourse approach to disease model facilitates quantifying if these exposures act independently or in concert to affect disease risk, predict patterns of disease, or alter disease trajectory. ${ }^{1}$ A variation on the life-course approach is to view the disease and its manifestations (physical, psychosocial, mental, or emotional) as exposures and the person's experience of life (health, well-being, goal attainment) over time as the outcome. This paradigm has been applied to the study of chronic conditions, the influences of which act over the long term and are likely to have a large impact on an individual's life course, including major life-changing decisions that are time-period specific, such as pursuing an education, choosing a career path, establishing relationships, and planning for a family. ${ }^{2-4}$

A cumulative life-course impact model includes elements with a negative influence on life trajectory, such as stigmatization and physical and psychological effects as a result of the disease, as well as positive elements such as developing coping skills, receiving family and social support, and obtaining successful medical and non-medical treatments. ${ }^{1}$ Along with fostering a better understanding of the 
individual's journey, applying a life-course approach helps identify factors that may mediate the cumulative effects of chronic conditions, recognize people and critical time windows that might be more vulnerable to impairment, and tailor interventions to these people, thereby targeting these time periods of maximal impact. ${ }^{1}$

In 2010, Kimball et $\mathrm{al}^{5}$ first used the term "cumulative life-course impairment" to describe the influence psoriasis has on a person's ability to achieve his or her full life potential in terms of relationships, social activities, work, and emotional well-being. Results from studies that examine health-related quality of life (QoL) associated with skin lesions report that psoriasis may lead to feelings of stigmatization, impact relationships, influence psychological well-being, and affect employment. ${ }^{5}$

\section{Life-Course Impact in Other Chronic Conditions}

The concept of life-course impact has been applied to other chronic conditions. For example, survivors of pediatric and adolescent cancer are at greater risk of developing mental health disorders later in life, particularly depression. ${ }^{6}$ Multiple adverse factors that can occur across the life course in these cancer survivors are likely to increase the risk of depression, including biologic (genetic and epigenetic), individual (lifestyle, education, economics), family and community (marital status, social networks), and societal (gender, race/ethnicity, geographic region) factors. ${ }^{6}$

\section{The Bigger Picture - Modifying Factors}

Many diseases and their symptoms have an impact on individuals at multiple points throughout their lives. These impacts may vary in magnitude and permanence based on when they occur and how they may be positively or negatively mediated or modified by demographic, sociologic, environmental, and medical factors. Socioeconomic status and disadvantages in early life have been implicated as factors affecting morbidity, functional limitations, and mortality. ${ }^{7}$ Considering the totality of all exposures and their temporality will reflect a more accurate understanding of a given condition and its effects on peoples' lives.

\section{Potential Life-Course Impact of Endometriosis}

\section{Chronic Pelvic Pain}

Life-impacting moderate-to-severe dysmenorrhea (pain during menstruation) is reported by about one-third of women, ${ }^{8}$ while chronic pelvic pain (CPP; noncyclical pelvic pain lasting for more than 6 months) is a disorder that occurs in up to $25 \%$ of the female population. ${ }^{9}$ While dysmenorrhea can be debilitatingly painful and present with nausea, irritable bowel syndrome, fatigue, and other symptoms that diminish QoL, CPP-in part due to its unpredictable onset and frequency throughout the menstrual cycle - is a well-established risk factor for diminished QoL, increased levels of depression and anxiety, decreased work productivity, and decreased sexual satisfaction. ${ }^{10-12}$

Furthermore, women with dysmenorrhea may be at a higher risk of developing CPP-related conditions like bladder pain syndrome, which may further negatively impact a patient's life course. ${ }^{13}$ Results from one recent study indicated that women with dysmenorrhea who also experience comorbid bladder pain hypersensitivity may be at an even greater risk for developing chronic pain. ${ }^{8}$ In another study, abnormal autonomic activity was identified in women with dysmenorrhea even 2 weeks after menses. ${ }^{13}$ These studies highlight the importance of understanding how chronic pain develops and how to treat it. ${ }^{8,13}$ Additionally, a British study of 1671 reproductive-aged women found that of the $24 \%$ of women with CPP, $11 \%$ also reported dysmenorrhea, $1.4 \%$ reported dyspareunia (painful intercourse), and $8 \%$ reported all three conditions. ${ }^{14}$ Women with CPP had lower scores in QoL related to physical and mental health and greater sleeprelated difficulties (eg, difficulty falling asleep or staying asleep) compared with the women who had dysmenorrhea only. Additionally, women with CPP reported a higher number of days off from work because of pelvic pain in the last 12 months compared with women who had dysmenorrhea only. In the United States, CPP is associated with a large economic burden, with approximately $\$ 881.5$ million spent on direct healthcare costs each year. Overall costs, including out-of-pocket payments and costs related to work absenteeism, total approximately $\$ 2$ billion each year. $^{15}$

\section{Endometriosis}

Several hypotheses exist for the etiology and pathogenesis of endometriosis and ultimately the etiopathogenesis of endometriosis is complex with various contributing factors leading to the development of this disease and its various phenotypic presentations. ${ }^{16,17}$

Newer research suggests the etiopathogenesis of endometriosis may be more complicated, attributing to genetic 
deregulation and $\mathrm{Wnt} / \beta$-catenin leading to mesodermic aberrations and deregulation, thus resulting in aberrant stem cell placement. The genetics and epigenetics underlying endometriosis are actively being studied, and a number of relevant gene targets have been identified, but collectively these only explain about $5 \%$ of the variance. $^{18}$

Further, the peritoneal microenvironment may be altered by multiple factors, such as immune cells and proinflammatory cytokine activation, which may in turn result in ectopic endometrial cell proliferation and survival. ${ }^{19}$ The etiology of pelvic pain disorders has also been extensively studied from a neurobiological angle, and aberrations in both local nerve involvement triggering peripheral sensitization, as well as marked changes in cortical and spinal sensory pathways leading to central sensitization are increasingly recognized as central to the pain symptoms that are so common in these women. ${ }^{20-24}$

Women with endometriosis often present with severe pain and infertility. ${ }^{25}$ The symptoms associated with endometriosis - ie, chronic pelvic pain, dysmenorrhea, dyspareunia, dysuria, dyschezia, chronic fatigue, and infertilityhave a substantially negative impact on the physical, mental, sexual, and social well-being of affected women. ${ }^{26}$

In an analysis of the US Health Interview Survey, 50\% of women reporting endometriosis also related that they had stayed in bed all day because of their condition at some time during the past year, with an average number of 17.8 bed days per year. ${ }^{27}$ Results from a recent study showed that women with endometriosis miss more days of work compared with healthy women, resulting in a substantial loss of work productivity. ${ }^{28}$ The study reported a mean annual cost per endometriosis patient of $\$ 16,573$ compared with $\$ 4733$ for women without endometriosis. Despite the substantial effect that endometriosis has on women, their families, and the economy, public and professional awareness of the condition remains poor. Consequently, many women experience significant delays before receiving a diagnosis of endometriosis. ${ }^{11,29,30}$ After receiving a diagnosis, many women experience unpredictable responses to surgical and medical therapies. ${ }^{31}$

Symptoms of endometriosis emerge and, for many, intensify during a number of critical life stages-adolescence through childbearing years-when girls form their social networks and define life goals, and women commence career-specific education, enter the work force, establish stable intimate relationships, and have children. ${ }^{32}$
Endometriosis, therefore, may exert its peak impact at times when major life-changing decisions are made. The consequences (ie, repercussions on health trajectories and well-being) of the symptoms associated with endometriosis (pain, fatigue, infertility) have not been thoroughly explored. Alteration in life course because of endometriosis and its associated symptoms is possible given its adverse effects on individuals' QoL, participation in daily activities, physical functioning, social functioning, sleep, sexual health, intimate relationships, relationships with friends and family, thoughts on family planning, fertility, childcare, educational attainment, career selection and work productivity, energy and vitality, mental health, and emotional well-being. ${ }^{33}$

\section{Beyond the Disease, Understanding the Impact on Life Potential}

As with other chronic conditions, most studies that examine endometriosis focus on specific areas of the disease, such as social, psychological, or physical impact at an isolated point in time. ${ }^{3,5}$ There is limited evidence from studies examining how symptoms and disease aspects impact decisions, life potential, and major life events of women with endometriosis over time. ${ }^{3,5}$ Application of the life-course approach to endometriosis may yield a deeper understanding of the condition's impact on an individual's life trajectory and thus elucidate critical points for intervention to maximize health and well-being. Life-course impact could be a useful lens through which to view the cumulative direct and indirect consequences of this prevalent disease. Existing studies admittedly come from small populations and uncontrolled study designs or often cover only short-term time intervals, which may fail to fully evaluate the breadth and chronicity of relevant symptoms. $^{11,34,35}$

A few recent narrative reviews have thoroughly explored the impact of endometriosis on specific areas, including sexuality, ${ }^{36}$ quality of life, and psychosocial well-being. ${ }^{37,38}$ These reviews suggest that endometriosis may impact many areas of women's lives and emphasize the importance of multidisciplinary care. ${ }^{36-38}$ However, to evaluate influences of endometriosis on a woman's life course, we need to assess how the combination of symptoms impacts personal experience with diagnosis and treatment, and how physical and emotional sequelae alter an individual's health trajectories and overall life satisfaction. We performed this quasi-systematic, narrative review to summarize the potential influences of endometriosis and 
its associated symptoms on life domains and examine the resulting impact on women's life goals and trajectory.

\section{Influence of Endometriosis on Life Domains}

The first step in developing a framework for analyzing the life-course approach for endometriosis is identifying the impairments associated with the disease and linking them to life milestones or major life-changing decisions. To identify known influences of endometriosis that may have a direct or indirect effect on life course and decisionmaking, we performed a search of the MEDLINE database using the following combination of terms: "endometriosis and women and impact", "effect", "influence" or "consequence and education", "quality of life", "health-related quality of life", "sexual dysfunction", "sexual health", "sexual satisfaction", "employment”, "profession", "professional”, “career”, “work”, "productivity”, “absenteeism”, "presenteeism" (reduced work functioning due to illness while at work), "income", "salary", "comorbidities", "occupation", "childbearing", "family planning", "relationships", "marriage", "divorce", "life impact", "life course", "life stage", "life satisfaction", "social life", "disability", "selfesteem", "stigma", "mental health", "physical health", "distress", and "well-being". Citations retrieved were limited to primary articles available in English and published during a 10-year period between February 2009 through February 2019. Additional relevant studies were identified from the reference lists of articles found through the literature search; thus, some referenced articles may fall outside the 10-year cut-off date.

The identified sources $(n=51)$ included 37 crosssectional, 10 case-control, and 4 cohort design articles (summarized in Table 1 Life-course impact). Most of the study populations were from Europe $(n=30)$ or North America $(n=13)$. The majority $(n=47)$ of studies were published in specialty journals, most often those dedicated to reproductive health and obstetrics/gynecology. The four studies that were published in journals that target a more general audience were descriptive, interview-based studies of small sample sizes or were retrospective analyses of a single-center study or a claims database, and typically focused on just a few aspects of endometriosis, such as emotional well-being, employment, or QoL. ${ }^{28,39-41}$ All articles we identified that address the impact of endometriosis on the life course are summarized by participants, design, and characteristics in the context of the broader endometriosis community (see the
Table I Summary of Endometriosis Publications

\begin{tabular}{|c|c|}
\hline Publications & $\mathbf{N}=\mathbf{5} \mathbf{I}$ \\
\hline \multicolumn{2}{|l|}{ Type of data } \\
\hline Cross-sectional study ${ }^{\mathrm{a}}$ & 37 \\
\hline Questionnaire-/interview-based study & 19 \\
\hline Questionnaire & 15 \\
\hline Interview & 4 \\
\hline Questionnaire and interview & I \\
\hline Conventional & 12 \\
\hline Web-based survey & 5 \\
\hline Case-control study & 10 \\
\hline Cohort study & 4 \\
\hline Prospective & 2 \\
\hline Retrospective & 2 \\
\hline \multicolumn{2}{|l|}{ Study Region ${ }^{\mathrm{b}}$} \\
\hline Europe & 30 \\
\hline North America & 13 \\
\hline Asia-Pacific & 5 \\
\hline South America & 4 \\
\hline Africa & 3 \\
\hline \multicolumn{2}{|l|}{ Type of Journal } \\
\hline General & 4 \\
\hline Specialist & 47 \\
\hline Reproductive health & 20 \\
\hline OB/GYN & 18 \\
\hline Women's health & 4 \\
\hline Pain management & I \\
\hline Managed care & I \\
\hline Pediatrics & I \\
\hline Sociology & I \\
\hline Psychology & I \\
\hline
\end{tabular}

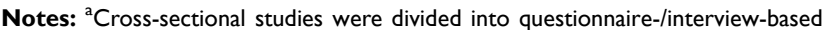
studies, conventional studies that did not use a questionnaire/interview or used one ad hoc, and web-based surveys. 'Studies including countries from more than one region are included in each region represented; sum is larger than the total number of studies.

Supplementary Table 1), and are reviewed here in a quasisystematic manner.

We stress that the influence of asymptomatic endometriosis (ie, the presence of endometriotic lesions without associated pain, menstrual symptoms, sexual dysfunction, or infertility) in some women is apt to have a far less or even negligible impact on the life course compared with women who experience moderate or severe symptoms, particularly those who are refractory to treatment. Moreover, life experiences and the influence of disease on life course are likely to be different in women with endometriosis-associated pain compared with women whose primary disease manifestation is infertility. Further, symptom profile and severity may affect participation, leading to a bias either toward or against women 
with severe life-impacting symptoms. For example, depending on the study design, women with more life-impacting symptoms may be driven to participate and share their stories or decline because participation seems overwhelming or unfeasible. Thus, selection bias may skew distributions and interpretation of the results and diminish generalizability to the typical woman with endometriosis. ${ }^{42,43}$ Social and cultural factors may shape women's experiences with endometriosis and skew study results, depending on the population examined. Although limited research explores this issue, several studies have postulated that cultural and social definitions surrounding what constitutes "normal" menstrual pain may influence whether women seek diagnosis and treatment for endometriosis, as well as the timing of treatment, potentially leading some groups of women to experience longer diagnostic delays, delayed pain relief, and potentially a greater lifecourse impact. ${ }^{27,44}$ Social and cultural factors may also influence the degree of disruption endometriosis symptoms have on women's lives. ${ }^{45}$ Furthermore, the studies we identified did not report the inclusion of transgender men or women, which precludes any analysis of the effect of endometriosis on the lives of transgender men or women.

\section{Educational Attainment}

We identified five studies in women with endometriosis that address the impact of endometriosis on the educational component of the life course. ${ }^{31,32,46-48}$ In an analysis of qualitative interviews of women with diagnosed endometriosis $(n=13)$ recruited after treatment for chronic pain at a pain clinic in Sweden, endometriosis was cited by participants as a reason for lost opportunities related to their education and careers. ${ }^{31}$ In another retrospective, self-administered, questionnaire-based study of women with endometriosis at community and specialist clinics in Sweden, ${ }^{32} 23.2 \%$ of 431 survey participants indicated that they had not pursued further education because of endometriosis; of note, women in this study tended to have a higher level of education than age- and gender-matched populations, perhaps due to access to care bias among women whose endometriosis is successfully diagnosed.

Pain appears to be a negative driver of the educational impacts of endometriosis. ${ }^{31}$ Of adolescents $(n=295)$ and adults $(\mathrm{n}=107)$ with surgically confirmed endometriosis who participated in a cross-sectional study within an ongoing longitudinal women's health study at two centers, a larger proportion ( $61 \%$ and $60 \%$, respectively) reported moderate-to-extreme interference with work or school due to endometriosis-associated pain. ${ }^{47}$ Moreover, in a large web-based survey of adolescent girls $(n=3998)$ conducted in Sweden, ${ }^{48}$ dysmenorrhea, regardless of an endometriosis diagnosis, was linked to school absences. Although this could indicate that dysmenorrhea and perhaps pain in general, rather than endometriosis per se, causes greater school absences, it is expected that a large percentage of the study participants had undiagnosed endometriosis. Furthermore, in a French study examining the adolescent history of women undergoing surgical management, deep endometriosis has been shown to be associated with more school absenteeism during menstruation than other forms of endometriosis (37.7\% [ $\mathrm{n}=98]$ vs $25.2 \%$ [ $\mathrm{n}=131]$, respectively). ${ }^{46}$ These findings on educational impacts attributed to endometriosis-associated pain are consistent with other chronic pain conditions (such as adolescent fibromyalgia) in young women, which are also associated with increased risk of reduced educational attainment. ${ }^{49,50}$

\section{Employment and Career}

We identified 15 studies in women with endometriosis that address the impact of endometriosis on the employment and career components of the life course. ${ }^{11,28,32,34,35,41,51-59}$ This included eight cross-sectional studies in Europe and the United States that reported a considerable deleterious influence of endometriosis on work productivity and capacity as well as career and salary growth. ${ }^{11,35,41,51-53,55,56}$ Using an established registry, Fourquet et $\mathrm{al}^{52}$ conducted a survey to assess outcomes in 107 women with selfreported, surgically diagnosed endometriosis. Forty percent of respondents believed that their career growth was directly and negatively affected by the consequences of endometriosis, including experiences of absenteeism, poor performance, failure to be promoted, not receiving bonuses, missed professional seminars, and lost clients. Women who were more likely to report that their work in the home and professional career was affected by endometriosis experienced menstrual pain, incapacitating pain, abdominal pain, and/or depression (odds ratios [ORs], 22.8 [95\% confidence interval $\{\mathrm{CI}\}, 2.3-226.7$ ], 35.2 [95\% CI, 4.3-274.6], 5.2 [95\% CI, 2.3-226.7], and 17.2 [95\% CI, 2.2-142.9], respectively). In a second survey within this population, women with endometriosis $(n=193)$ reported an average of 7.41 hours per week of missed work when symptoms were at their worst, and work-related losses of $13 \%$ due to absenteeism, $65 \%$ due to presenteeism, and $64 \%$ from decreased work productivity, as measured on the Work Productivity and Activity Impairment Questionnaire. ${ }^{51}$ Of note, women in these two studies 
were classified as having severe disease, and their experiences may not be entirely generalizable to the broader population of women with endometriosis.

In an online survey conducted in 2012, women in the United States who were aged 18-49 years with selfreported endometriosis $(n=1318)$ estimated average weekly employment and household productivity losses of 5.3 and 2.3 hours, respectively, due to presenteeism, and productivity losses of 1.1 and 2.5 hours, respectively, due to absenteeism. ${ }^{55}$ Productivity losses were greater among women with severe vs mild endometriosis-associated symptoms (total employment productivity losses, 15.8 vs 1.9 hours; total household productivity losses, 10.1 vs 2.5 hours). These results are consistent with data from a study of premenopausal women with surgically diagnosed endometriosis $(n=1418)$ conducted by Nnoaham et $\mathrm{al}^{11}$ in which clinically and statistically significant associations were detected between symptom severity and absenteeism ( $P=0.02)$, presenteeism $(P=0.03)$, and work productivity loss $(P=0.01)$ and between the presence of severe pelvic pain and work productivity loss $(P<0.001)$.

Hansen et $\mathrm{a}^{53}$ reported that Danish women with diagnosed endometriosis (via laparoscopy or pelvic magnetic resonance imaging; $n=610$ ) self-identified use of more sick days $(41 \%$ with endometriosis vs $25 \%$ without endometriosis taking sick days in the last 4 weeks), more frequent workday disturbances due to symptoms, and lower work ability compared with women without endometriosis $(n=751)$. Tiredness, frequent pain, more severe pain, greater use of sick days, and depression at work were associated with decreased work ability. Interestingly, a longer delay in diagnosis was also associated with low work ability. A smaller proportion of women categorized as having poor work ability, as measured by the Work Ability Index, were diagnosed with endometriosis within 2 years of symptom onset compared with women categorized as having excellent work ability $(16.2 \%$ and $48.2 \%$, respectively). In contrast, a delay in diagnosis of 7 to 8 years was more common among women with poor vs excellent work ability ( $24.2 \%$ and $5.4 \%$, respectively).

Women with endometriosis have reported altering their career trajectories due to endometriosis, including taking time off work, opting for part-time employment, losing chances for promotion, giving up a favorite job, or choosing a less stressful job. ${ }^{34}$ Among 431 Swedish women with endometriosis who participated in a retrospective, selfadministered questionnaire-based study, 20.4\% reported having lost or quit a job at some point during their life due to endometriosis-related problems. ${ }^{32}$ Moreover, $17.4 \%$ of women indicated that they had altered their career choice and $24.6 \%$ had reduced the number of hours they worked because of endometriosis.

In a matched case-control study in central Europe, women with endometriosis $(\mathrm{n}=505)$ and controls (women presenting for routine gynecological care or benign gynecological surgery) were asked to complete a questionnaire assessing professional life. Women with endometriosis who agreed to complete the questionnaire responded that they were more likely to report working in their desired profession (adjusted OR, 1.84 [95\% CI, 1.15-2.94]) and were more likely to report health-related limitations that influenced career choices (OR, $4.79 \quad[95 \%$ CI, 2.30-9.96]). ${ }^{41}$ Endometriosis was also associated with a greater likelihood for women to report taking sick leave (OR, 3.52 [95\% CI, 2.02-6.13]) and report lost work productivity (OR, 3.08 [95\% CI, 2.11-4.50]).

A study of 630 women consecutively recruited at a tertiary endometriosis research center in Italy reported that women with symptomatic endometriosis were significantly less likely to be employed compared with women without endometriosis (OR, 0.35 [95\% CI, 0.18-0.65]) or women with asymptomatic endometriosis (OR, 0.36 [95\% CI, 0.17-0.79]). ${ }^{54}$ Unemployed women with endometriosis had a greater severity of dysmenorrhea, dyspareunia, chronic pelvic pain, and dyschezia compared with employed women with endometriosis.

Loss of productivity has an associated $\operatorname{cost}^{28,58,59}$ as do career modifications that result from symptom-driven declines in educational attainment. A 2009 Canadian cross-sectional assessment of healthcare resource utilization estimated the mean annual societal cost of endometriosis to be $\$ 5200$ (CAD) per patient, of which $78 \%$ was attributed to lost productivity and leisure time. ${ }^{58}$ An analysis of medical claims data of endometriosis-associated costs performed in the United States reported significantly greater annual average per-person work loss costs among women with endometriosis compared with a nonendometriosis comparison cohort, including losses due to absenteeism ( $\$ 5383$ vs $\$ 4224$ [in 2014 USD]; $P<0.0001$ ) and short-term disability ( $\$ 1709$ vs $\$ 402 ; P<0.0001){ }^{28}$ These data highlight the economic ramifications of impairments in work ability experienced by women with endometriosis. The impact of endometriosis on employment and its economic consequences are also mirrored by other chronic pain conditions. One study of 2459 employees with chronic pain conditions working at several large 
US corporations found that pain impacted work attendance and had a negative economic impact. ${ }^{60}$ However, many chronic pain conditions, like backpain or pain related to injuries, may be more common in older patients. Indeed, the mean age in this study was 45 years. ${ }^{60}$ Because most women may begin feeling endometriosis-related pain during their teens, ${ }^{30}$ the cumulative impact of endometriosis on employment and careers may be higher.

\section{Social Life}

We identified 11 studies in women with endometriosis that address the impact of endometriosis on the social life component of the life course. ${ }^{29,31,32,34,48,51,52,61-64}$ A high proportion of women with endometriosis report impairment in social functioning as a result of their condition. $^{34,51,52}$ Approximately half of women with selfreported, surgically diagnosed endometriosis $(n=107)$ who were enrolled in a long-standing registry expressed perceived physical limitations to social activities. ${ }^{52}$ The presence of incapacitating pain or dyspareunia was associated with social impairments in this cohort. In a qualitative study using structured interviews, effects on women's social lives were one of the most noted impacts of endometriosis across age groups. ${ }^{34}$

Decreased social interaction and withdrawal from social activities may be a reaction to pain, bleeding, fatigue, depression, feelings of isolation, dissatisfaction with body appearance, low self-esteem, or lack of self-confidence. ${ }^{29,31,32,62,63}$ The role of pain in social withdrawal is underscored by results from a web-based questionnaire of Swedish adolescents in which $59 \%$ of participants reported avoiding social activities because of dysmenorrhea. ${ }^{48}$ Moreover, pain is associated with an increased likelihood of fatigue (OR, 2.22 [95\% CI, 1.52-3.23] $)^{61}$ as demonstrated by results from a multicenter case-control study in which 1120 women from Switzerland, Germany, and Austria were recruited. In addition, in a cross-sectional web-based survey study, fatigue/weariness/anemia has been shown to correlate with impaired perceived quality of social support $(P<0.01)$ as well as self-rated emotional well-being $(P<0.05) .{ }^{64}$ Women report social support can take many forms, including doctors, therapists, friends, or even internet forums and a lack of support by doctors, in particular, may contribute to a delay in the diagnosis and treatment of endometriosis. ${ }^{65}$ These collective findings on the impact of endometriosis on social life are also consistent with reports of other chronic pain conditions in adolescents, including juvenile primary fibromyalgia syndrome, sickle cell disease, or migraines. ${ }^{66,67}$

\section{Fertility}

We identified seven studies that address the impact of endometriosis on the fertility component of the life course. $^{11,31,34,45,62,63,68}$ Women with a history of endometriosis have double the risk for incident infertility compared with women without a history of endometriosis (hazard ratio [HR], 2.12 [95\% CI, 1.76-2.56]), ${ }^{68}$ with about $16-40 \%$ of women with endometriosis experiencing difficulty conceiving. ${ }^{11,57,68}$ For these women, the experience of infertility adds to the burden of endometriosis, negatively affecting psychological health, marital relationships, social interactions (eg, avoiding friends and relatives with children), and financial status (due to fertility treatment) as well as causing feelings of stigmatization and hopelessness. $^{34,62}$ Moreover, some young women with endometriosis worry about finding a significant other who will be accepting of possible infertility. ${ }^{63}$

With the increased risk for infertility, family planning is of considerable concern to women with endometriosis. Women with debilitating pain may face the difficult decision between treatment for pain relief and delaying or foregoing pregnancy (for those who undergo hysterectomy). ${ }^{45}$ In interviews conducted as part of the ENDOPART study in the United Kingdom, 18 of 22 couples reported that endometriosis affected their plans to have children. ${ }^{45}$ Some couples reported having children earlier than they had planned because there was potential for future infertility. Indeed, some healthcare providers counsel women to begin planning a family at a younger age because of their endometriosis and risk of infertility, ${ }^{31,34}$ which may induce anxiety associated with premature fertility choices. This emotional impact of endometriosis on infertility is also observed among women with polycystic ovarian syndrome who are also at high risk of infertility. ${ }^{69}$

\section{Personal Relationships}

We identified 13 studies in women with endometriosis that address the impact of endometriosis on the personal relationships component of the life course. ${ }^{34,45,62,70-79}$ The category of "personal relationships" is inclusive of social and family connections as well as intimate partner relationships. Endometriosis may interfere with all types of interpersonal relationships, ${ }^{34,62}$ but it is sexual health that has garnered the most research interest. Research to date has focused on challenges faced by cisgender women with endometriosis; to our knowledge, no studies have examined the ways in which endometriosis may impact the 
personal relationships of transgender individuals. Studies have consistently reported impairment in sexual function in women with endometriosis that causes strain on intimate relationships. ${ }^{45,62,70,72,75,79}$

In a multicenter Austrian and German study of 125 women with histologically confirmed endometriosis and dyspareunia, most women (78\%) reported sexual distress, as measured on the Female Sexual Distress Scale, and $32 \%$ reported sexual dysfunction, as measured on the Female Sexual Function Index (FSFI). ${ }^{74}$ Only $21 \%$ of women reported neither sexual distress nor sexual dysfunction. Pain intensity during/after sexual intercourse, measured using a numerical rating scale (range, 1-10), was greater among women who experience sexual dysfunction vs women who do not (mean scores, 6.5/5.7 and 5.2/4.0, respectively; $P<0.01$ ). Data from an observational, cross-sectional study in the Netherlands revealed that women with endometriosis $(\mathrm{n}=83)$ were more likely to experience dyspareunia $(53 \%$ vs $15 \% ; P<0.001)$ and reported greater impairment in sexual functioning (median FSFI, 25.4 vs $30.6 ; P<0.001)$ than did women without endometriosis $(\mathrm{n}=40){ }^{72}$ In this cohort, dyspareunia and depressive symptoms were independent predictors of sexual dysfunction. More than half of women feared losing their partner because of the impact of endometriosis on sexual functioning.

Several studies have attempted to correlate sexual dysfunction with the location of endometriosis. . $^{71,73,76,78}$ Vercellini et $\mathrm{al}^{78}$ reported impairment of sexual functioning among Italian women with endometriosis, regardless of type (rectovaginal, peritoneal, or ovarian). Sexual interest, satisfaction with their sex life, and sexual pleasure were all affected by endometriosis. In a Brazilian crosssectional study of women with suspected or diagnosed deep endometriosis, more than one-third met the criteria for sexual dysfunction according to the FSFI. ${ }^{76}$ Results from analyses using multiple logistic regression revealed a significant inverse correlation between higher overall FSFI score and rectosigmoid endometriosis lesions $(P<0.01)$. These results were consistent with findings from an Italian cross-sectional study in which sexual functioning was compromised to a greater extent in women with severe dyspareunia compared with women with mild or moderate dyspareunia. ${ }^{77}$ Sexual dysfunction in this cohort was associated with reduced QoL. Cozzolino et al ${ }^{71}$ reported that the presence of rectovaginal nodules in Italian women with deep endometriosis was more strongly associated with impaired sexual activity and sexual function than other lesion locations. In agreement with these collective findings, other chronic conditions, like musculoskeletal pain, have also been shown to have a negative impact on personal relationships. ${ }^{80,81}$

\section{Mental Health}

We identified 16 studies in women with endometriosis that address the impact of endometriosis on the mental health component of the life course. ${ }^{29,31,32,34,39,41,44,62-64,82-87}$ Endometriosis with or without chronic pelvic pain may have a significant association with mental health in women, as exemplified by changes in temperament (mood swings, easily angered) to feelings of distress, depression, anxiety, and negative perceptions of self (low self-esteem, self-consciousness). ${ }^{34,62,64,84}$ This association may also be stronger in women with a higher endometriosis symptom burden. ${ }^{64,87}$ In an analysis of comorbidity among women with and without endometriosis, women with the disease were at increased risk of developing depression and anxiety compared with women without disease (HR, 1.5 [95\% confidence interval, 1.4-1.6]) ${ }^{84}$ Women with endometriosis articulate feelings of worthlessness, guilt, and frustration connected with diseaserelated limitations on participation in daily activities, social functioning, independence, and interpersonal relationships. $^{31,32,62}$ Frustration may also stem from a woman's inability to manage or predict her pain and the feeling that endometriosis/endometriosis-associated pain controls her life. ${ }^{32,63,83}$ Negative emotions may be reinforced by the perception that others (even healthcare professionals) consider what they are experiencing to be "all in their heads". ${ }^{29,82}$

Results from a cross-sectional Italian study evaluating the presence of psychiatric comorbidities among women with endometriosis with and without pelvic pain revealed mental health disorders in 59\% of women surveyed $(\mathrm{n}=134)$; some of these issues included somatoform disorder, panic and other anxiety disorders, major and other depressive disorders, and eating disorders. ${ }^{87}$ Women rated pain symptoms on a visual analog scale while psychiatric symptoms were evaluated with a mental health disorders screening questionnaire. Women positive for a psychiatric disorder were significantly more likely to report severe endometriosis-associated pain than were women with a negative screening result ( $53 \%$ vs $22 \% ; P=0.003)$. The presence of mental health disorders was not significantly associated with the need for surgery, number of interventions, or infertility. Similar results were reported in an 
Italian case-control study in which women with surgically diagnosed endometriosis and healthy controls were evaluated for the presence of psychiatric disorders. There was a significantly higher prevalence of psychiatric comorbidities observed among women with endometriosis $(n=37)$ compared with healthy controls $(n=43)(54.0 \%$ vs $18.6 \%$, respectively; $P=0.001)$. ${ }^{39}$

Prevalence rates for depression and anxiety as high as $48 \%$ have been reported for women with endometriosis. ${ }^{39,83,85-87}$ In a small US (Puerto Rican) survey ( $\mathrm{n}=24), 45.8 \%$ of women ages 13-25 years with symptomatic endometriosis had moderate-to-severe anxiety and $33.4 \%$ had moderate-to-severe depression. ${ }^{83}$ Moderate-to-strong positive correlations were observed between the presence of anxiety $(r=0.55)$ or depression $(r=0.70)$ and reduced QoL in this cohort of women.

Depression and anxiety may have downstream impacts on other components of the life course. In a previously mentioned matched case-control study in Europe, ${ }^{41}$ women with endometriosis self-reported depression and anxiety that was significantly related to increased sick leave. Furthermore, women with endometriosis were more likely to consciously consider health-related limitations when making career decisions (OR, 4.79 [95\% CI, 2.30-9.96]) compared with matched controls (women presenting for routine gynecological care or benign gynecological surgery).

Facchin et $\mathrm{al}^{44}$ conducted structured interviews with 210 Italian women who had a clinical or surgical diagnosis of endometriosis. Investigators reported several correlations between endometriosis-related factors and mental health in women with endometriosis, including associations between being in a stable intimate relationship and decreased rumination, shorter time since diagnosis and greater anxiety, and greater pelvic pain severity and poorer mental health. The impact on mental health was evaluated using a selection of assessment scales. Moreover, lower self-esteem, body esteem, and emotional self-efficacy were associated with poorer mental health measures. These collective findings on the psychological well-being of women with endometriosis are consistent with other conditions involving chronic pain, such as chronic back pain or migraines. ${ }^{88,89}$

\section{Quality of Life}

We identified 10 studies in women with endometriosis that address the impact of endometriosis on the QoL component of the life course. ${ }^{10,11,32,40,57,64,83,90-92}$ Results from these studies indicate a general trend of health-related QoL negatively correlating with symptom burden and positively correlating with age in women with endometriosis.

The negative correlation of health-related QoL with perceived symptom burden and severity is shown in several articles. For example, in a multinational study that included 1418 premenopausal women undergoing laparoscopy, health-related QoL scores were better among women who were employed and who did not report pelvic pain and were worse among women with more severe pelvic pain or those who experienced a longer diagnostic delay. $^{11}$

In a Hungarian study of 145 women with endometriosis, pain symptoms, depression, anxiety, distress, and difficulties in emotional regulation have been linked to impairment in health-related QoL. ${ }^{92}$ Pain symptoms were associated more closely with the physical domain of health-related QoL, whereas psychological variables and emotional regulation had a stronger association with the mental domain. The severity of pain experienced by women with chronic pelvic pain was inversely related to QoL, with a greater magnitude of pain associated with lower QoL scores. ${ }^{40}$ The severity of dysmenorrhea, in particular, negatively correlated with QoL scores for the physical $(r=-0.382 ; P=0.03)$, social $(r=-0.221 ; P=0.01)$, and environmental $(r=-0.373 ; P=0.03)$ domains. $^{91}$ No significant differences in QoL measures between Brazilian women with chronic pelvic pain who have endometriosis $(n=49)$ and those with chronic pelvic pain without endometriosis $(n=35)$ were observed in a case-control study by Tripoli et al; ${ }^{10}$ both groups had impaired QoL compared with women who had neither chronic pelvic pain nor endometriosis $(n=50)$. This finding suggests that having pain itself, rather than endometriosis specifically, is the driver of impaired QoL.

A negative correlation between symptom burden and health-related QoL is also seen with other chronic conditions. For example, a longitudinal study examining symptom burden and QoL in cancer survivors in a cancer rehabilitation program found that perceived highsymptom severity was associated with a significantly poorer QoL at baseline, regardless of the site of cancer. ${ }^{93}$

Conversely, despite the strong link to pain symptoms, impairments in QoL have also been observed among women with endometriosis without chronic pelvic pain. Abd El-Kader et $\mathrm{al}^{57}$ reported that the presence of endometriosis-associated pelvic adhesions was associated with reduced QoL, measured by the Global Quality of Life Scale, in a cross-sectional study of 109 Egyptian women 
without chronic pelvic pain undergoing laparoscopy for infertility-related reasons $(P=0.002)$. Women without endometriosis-related adhesions were less likely to have reduced QoL (10.3\%) compared with women with adhesions (34.1\%). One limitation of this study is that QoL scores were dichotomized, which could mask more subtle effects on life-quality ratings. Adhesion-associated pain was not examined in the study.

Another trend in articles addressing the impact of endometriosis on the QoL component of the life course was a positive correlation between age and health-related QoL. In the aforementioned multinational, web-based survey study of women with self-reported endometriosis, ${ }^{64}$ younger women (aged 18-29 years) had worse scores for pain, emotional well-being, and social support compared with older age groups, suggesting endometriosis negatively impacts life course from an early stage. Similarly, an influence of age on endometriosis-related symptoms and QoL was observed in responses by Swedish women $(\mathrm{n}=431)$ to a self-administered questionnaire. ${ }^{32}$ Younger women (aged $<30$ years) reported a greater symptom burden than older women, including a higher prevalence of severe dysmenorrhea, nonmenstrual pain, problems sitting or standing because of pain, and deep dyspareunia. Across the study population, scores on the 36-item Short Form Survey (SF-36) were considerably lower in women with endometriosis compared with age-matched controls collected from an SF-36 normative database, particularly for the subscales of vitality, role physical, and general health.

Although not as robustly studied as adults, some data are available on the impact of endometriosis on QoL among adolescents and young women. ${ }^{83,90}$ Women aged 25 and younger with endometriosis $(n=360)$ surveyed at baseline as part of the longitudinal "Women's Health Study: From Adolescence to Adulthood" had lower SF-36 physical and mental component summary scores as well as lower scores on all eight health concept subscales compared with adolescent girls and women without endometriosis $(\mathrm{n}=207 ; P<0.001) .{ }^{90}$ Poorer QoL scores were observed among those women with an earlier age at menarche $(<11$ years), more severe pelvic pain, or a longer delay in diagnosis ( $>3$ years). Moreover, adolescent and young adult women with endometriosis who use maladaptive coping strategies were more likely to have lower QoL scores and poorer mental health status. While endometriosis does not itself cause maladaptive coping strategies, it is generally true that individuals who have poorer coping skills have poorer psychological health, which corresponds to worse outcomes across multiple disease states, including endometriosis. $^{83}$

Meanwhile, studies examining both polycystic ovarian syndrome and menopause have noted a decrease in QoL with advancing age ${ }^{94}$ in contrast to the studies on endometriosis described here. However, other authors have observed that health-related QoL should be viewed as multidimensional with a trajectory that may differ among diseases. ${ }^{57,95,96}$ Endometriosis symptoms typically improve as women reach the end of the reproductive age range, ${ }^{32,33}$ potentially explaining the discordance.

\section{Commentary: Life-Course Effects of Endometriosis}

Overall, this quasi-systematic review of the literature reveals that endometriosis influences numerous aspects of women's lives. Individual symptoms and impairments have multiple downstream consequences that were often interrelated. We have diagrammed this network of associations in Figure 1. Discrete influences at specific time points and larger impacts experienced over the course of years to decades together shape the trajectory of an individual's life. Based on findings in the literature, we have developed Figure 2 that illustrates the theoretical effects that endometriosis-related life events have on a life-course trajectory. For the individual depicted, untreated (or inadequately treated) symptomatic endometriosis may begin to alter the life-course trajectory as early as adolescence and could continue to have effects throughout life until menopause. The trajectory illustrated in Figure 2 could be argued to represent a worst-case scenario where a woman develops symptoms around the time of menarche, thus having a critical developmental stage (for personality and social development and life planning) as well as a greater proportion of her life influenced by the presence of endometriosis. Had this woman experienced disease onset in her 30s, the impact on her life course may be lessened (although still readily apparent), as she would have already made certain important life decisions and achieved some of her life goals, perhaps completing an education or having children. Optimal treatment (ideally when symptoms begin) should lead to a better life course for a woman experiencing endometriosis compared with a woman whose endometriosis was left untreated, thereby matching a life course similar to that of a woman who does not have endometriosis. However, it is important to 


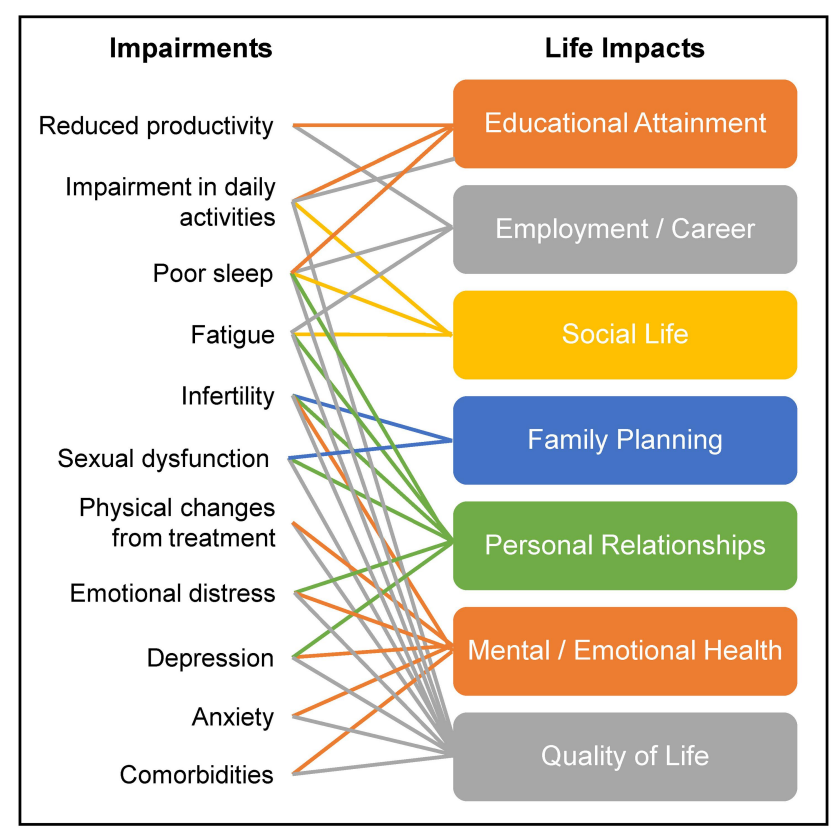

Figure I Connections between endometriosis-associated impairments and life impacts. note that dysmenorrhea and CPP are also prominent conditions in women ${ }^{8,9}$ that may also impact women's overall well-being and life course independent of endometriosis. ${ }^{10-12}$

The relative effect of endometriosis-related life events, such as those presented in Figure 2, will be modified by life stage. In semi-structured focus group discussions involving 35 women with a confirmed diagnosis of endometriosis who ranged in age from 17 to 53 years (mean, 31 years), participants ranked marital/sexual relationships, social life, physical effects, and psychological effects among the most important impacts of endometriosis. ${ }^{34}$ Secondary rankings of importance were modified by life stage. For adolescents, education was top of mind, whereas young adults were concerned with life opportunities and employment, and women aged 35 years and older more often cited the financial impact of endometriosis. As our understanding of developmental factors that influence women's response to endometriosis grows, we

\section{Life Course Impact of Untreated Symptomatic Endometriosis}

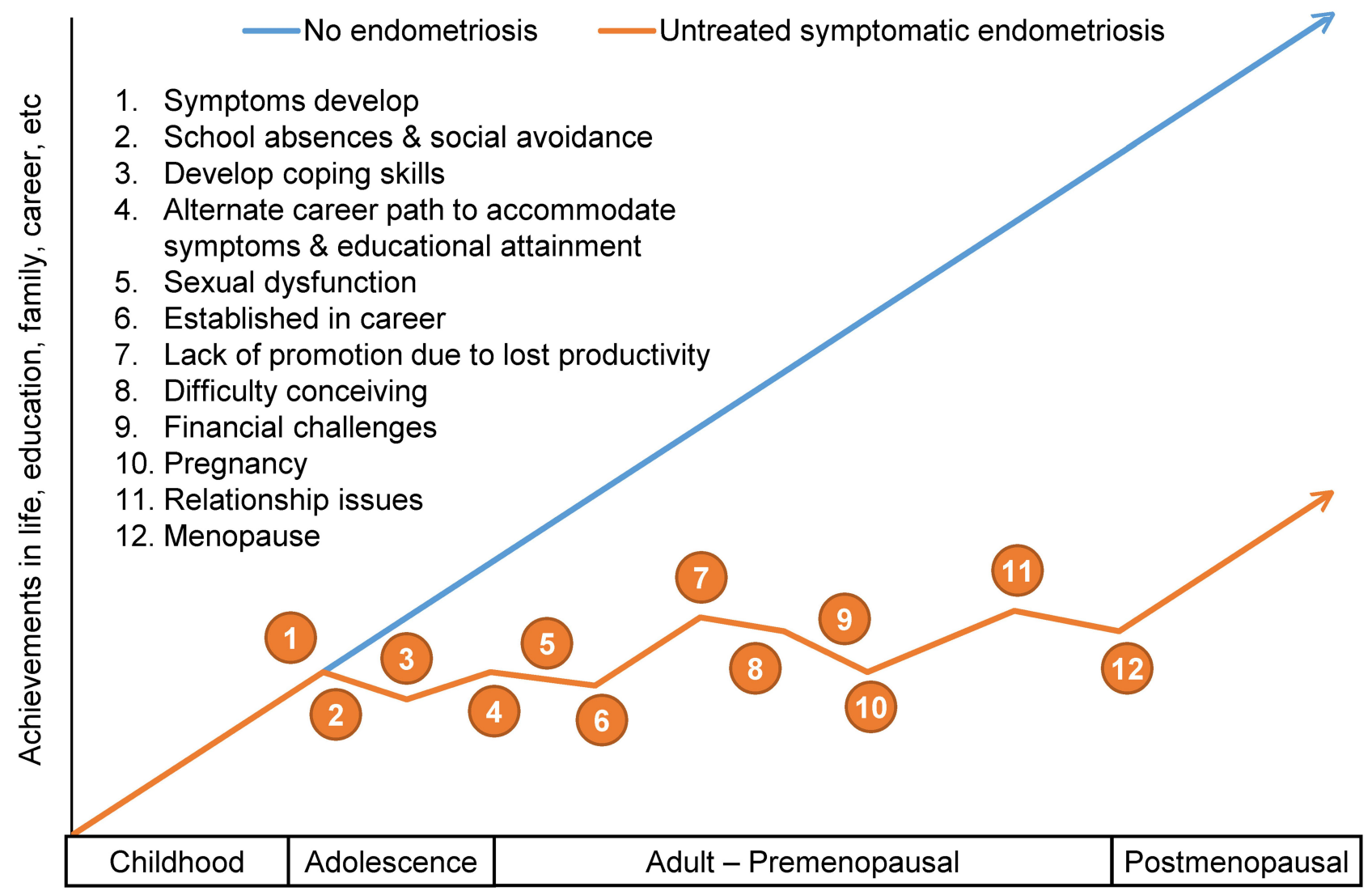

Figure 2 Theoretical effects of endometriosis on life-course trajectory. Life exposures and their influences on a patient's attainments in life, education, family, career, etc. A comparison of untreated or persistently symptomatic endometriosis vs no endometriosis. 
will be better able to identify women who are at risk for adverse outcomes and, hence, require greater levels of intervention and support. $^{34}$

The degree of impact that endometriosis has on a woman is likely to be highly variable and influenced by intrinsic and extrinsic mediating factors such as length of time between a woman's symptom onset and endometriosis diagnosis; the severity and frequency of pain; comorbidities; the number of therapeutic interventions and success rates; social support system, which could include social, cultural, and religious institutions as well as healthcare systems; coping mechanisms; and other factors (Table 2). A longer diagnostic delay, for example, is associated with low-work ability ${ }^{53}$ and poorer health-related QoL, ${ }^{11,90}$ whereas the severity of pain is linked to impairments in sleep quality, ${ }^{97}$ work inside or outside the home, ${ }^{52,53}$ sexual function, ${ }^{74}$ mental health, ${ }^{44}$ and QoL. ${ }^{40,90}$ Repeated surgical interventions and medical treatments, their side effects, and psychological consequences of repeated treatment failures may be a source of stress and direct health impact for women with endometriosis. ${ }^{98}$ As the number of surgeries and/or treatments increases, stress and risk of short-term and chronic side effects often increases; the same association is observed between a longer history of endometriosis and stress. Women with endometriosis or dysmenorrhea have been shown to have

Table 2 Potential Factors Mediating the Impact of Endometriosis on Life Course at the Individual Level

Age at symptom onset and eventual diagnosis
Delay in diagnosis
Social/family/spouse support
Psychological considerations (eg, abuse/early traumatic exposures,
stress, anxiety, depression)
Severity, frequency, and predictability a of pain
Opioid use
Infertility
Pregnancy/successful livebirth
Comorbidities and their symptoms
Response (or non-response) to treatment
Number of surgeries
Geographic location
Financial status
Access to healthcare
Hysterectomy
Menopause
Patient resilience
Complementary and alternative medicine coping mechanisms,
including mindfulness training or other mind-body interventions
Predisposition to pain/chronic pain syndromes

Note: aMany women report that although dysmenorrhea is their worst pain, nonmenstrual pelvic pain is more problematic because of its lack of predictability, which leads to hesitancy in planning and engaging in activities (SKA, clinical observations). aberrant cortisol levels, suggesting disturbances in responses in the hypothalamic-pituitary-adrenal axis that negatively impact stress management. $22,99-101$

\section{Conclusions}

The evidence presented herein supports the existence of multifactorial impacts of endometriosis that span the life course, from the point of symptom onset onward through decades of a woman's life. Endometriosis (and its associated symptoms) has been shown to hamper educational attainment, hinder work productivity, alter career choices and success, impair social life and activities, affect family choices, induce strain in personal relationships, negatively influence mental and emotional health, and adversely affect QoL. These multiple and pervasive effects are anticipated to materially alter the life-course trajectory of women with endometriosis. Unfortunately, current practice models too often result in a prolonged delay between symptom onset, diagnosis, and treatment of endometriosis, thereby increasing the impact on the life course. ${ }^{11,26}$ To minimize the negative impact of endometriosis on a woman's life course, early diagnosis and effective intervention in treating the disease in conjunction with comprehensive, long-term patient-focused care is required. Healthcare delivery models that are most likely to achieve success incorporate providers beyond gynecologists with a range of complementary skills, including primary care physicians, psychologists, nurses, pediatricians, adolescent medicine specialists, and others working and communicating together effectively. ${ }^{25}$ We hope that a focus on early detection with effective, comprehensive management and long-term goals may ultimately allow for a reduced impact by endometriosis on women's life course.

This review and commentary provide a preliminary framework for the assessment of endometriosis on the life course, yet several important research questions remain. We identify multiple intrinsic and extrinsic characteristics (eg, age, fatigue) that modulate the impact of endometriosis on life domains (either for the better or worse). Direct investigation is needed to identify which characteristics most strongly alter the life-course trajectory. The degree of influence that individual symptoms (eg, chronic pelvic pain, dysmenorrhea, infertility) have on life course is also largely unknown, as is the impact of these symptoms and environmental/social factors at different ages or life stages. Finally, to fully understand the life-course impact endometriosis has on the life course, studies that analyze longitudinal quantitative and qualitative data that measure all the affected life domains 
are needed. Understanding the effects of endometriosis beyond the symptoms of pain and infertility is an initial step toward supporting women in achieving their full life potential.

\section{Acknowledgment}

This study was supported by AbbVie Inc. AbbVie participated in the development, review, and approval of the manuscript. Medical writing support for the development of this manuscript, funded by AbbVie, was provided by Crystal Murcia, $\mathrm{PhD}$, Lamara D. Shrode, PhD, CMPP, Michelle R. Roberts, $\mathrm{PhD}$, Kelly M. Cameron, PhD, CMPP, Michael M. Schofield, $\mathrm{PhD}$, and Kersten Reich, MPH, CMPP, of JB Ashtin.

\section{Author Details}

ORCID: Stacey A. Missmer: ORCID: 0000-0003-3147-6768. Frank F. Tu: ORCID: 0000-0002-6348-6285. Sanjay K. Agarwal: ORCID: 0000-0002-8046-9807. Charles Chapron: ORCID: 0000-0003-2578-3163. Ahmed M. Soliman: Not Applicable. Stephanie Chiuve: Not Applicable. Samantha Eichner: Not Applicable. Idhaliz FloresCaldera: ORCID: 0000-0003-2130-4508. Andrew W. Horne: Not Applicable. Alexandra B. Kimball: ORCID: 0000-00019405-0479. Marc R. Laufer: ORCID: 0000-0002-6295-987X. Nicholas Leyland: ORCID: 0000-0003-3437-0723. Sukhbir S. Singh: Not Applicable. Hugh S. Taylor: Not Applicable. Sawsan As-Sanie: ORCID: 0000-0002-7166-1979.

\section{Author Contributions}

All authors made a significant contribution to the work reported, whether that is in the conception, study design, execution, acquisition of data, analysis and interpretation, or in all these areas; took part in drafting, revising or critically reviewing the article; gave final approval of the version to be published; have agreed on the journal to which the article has been submitted; and agree to be accountable for all aspects of the work.

\section{Disclosure}

SAM reports grants and personal fees from AbbVie and personal fees from Roche Diagnostics, outside the submitted work; has received research support from the National Institutes of Health, Department of Defense, and the Marriott Family Foundations; and has received honorarium for consultancy from AbbVie, Roche, and Celmatix. FFT reports personal fees from AbbVie and Myovant, and royalties from UpToDate, during the conduct of the study; has received grants from NIH, outside the submitted work; has received research support from NICHD-NIH, NIDDK-

$\mathrm{NIH}$; and has served as a consultant for AbbVie and Uroshape. SKA reports grants and personal fees from AbbVie and grants from SOBI, during the conduct of the study; grants and personal fees from AbbVie, outside the submitted work; has received research support from AbbVie and SOBI; and has served as a consultant for AbbVie. $\mathrm{CC}$ has served as a consultant for AbbVie, Bayer, and Ipsen. AMS reports being an employee of AbbVie Inc. and owning stocks in AbbVie Inc., during the conduct of the study; and in addition has a patent, US Patent App. 16/105,440 pending to AbbVie Inc. and a patent US Patent App. 16/105,396. SC reports salary from AbbVie, outside the submitted work. SE reports being an AbbVie full-time employee with salary, outside the submitted work. IF-C reports personal fees from Idhaliz Flores/PHSU, during the conduct of the study, has received research support from NICHD-

NIH; Bayer-Society for the Study of Reproduction; and the Puerto Rico Science, Research, and Technology Trust; and has served as a consultant for AbbVie. AWH reports consultancy fees paid directly to their employer and funds used for research from AbbVie, Roche Diagnostics, Ferring, and Nordic Pharma, and grants from MRC, NIHR, Chief Scientist's Office, Wellbeing of Women, Roche Diagnostics, Astra Zeneca, and Ferring, outside the submitted work; has received research support from MRC, NIHR, Wellbeing of Women, Roche Diagnostics, Astra Zeneca, and Ferring; and has served as a consultant for AbbVie, Roche Diagnostics, Ferring, and Nordic Pharma. ABK reports grants and personal fees from AbbVie, during the conduct of the study; has received research support and fellowship funding from AbbVie; and has served as a consultant for AbbVie. MRL reports grants from J Willard \& Alice S Marriott Foundation, NextGen Jane Scientific Advisory Board, Wolters Kluwer Editor Emans, Laufer, Goldstein's Pediatric \& Adolescent Gynecology 2020, and AbbVie Scientific Advisory Board, during the conduct of the study; has received research support from the J Willard and Alice S Marriott Foundation, and the Marriott Daughters Foundation; and has served as a consultant for NextJaneGen and AbbVie. NL reports grants from AbbVie, during the conduct of the study; personal fees from AbbVie, outside the submitted work; has served as a consultant for Allergan, Bayer, and AbbVie; and has received research support from Bayer, AbbVie, and Allergan. SSS reports grants and personal fees from Bayer, advisory board work and support CME education programs from Hologic, and research grants to 
their institution, advisory board work, and support CME education programs from AbbVie and Allergan, outside the submitted work; has received research support from AbbVie, Allergan and Bayer; and has served as a consultant for AbbVie, Bayer, Allergan, Merck, Hologic, and Myovant. HST reports grants from AbbVie, outside the submitted work; has received research support from Dot Lab; and has served as a consultant for Bayer, Obseva, and AbbVie. SAS reports personal fees from AbbVie, Bayer, Merck, Myovant Sciences, and UpToDate, during the conduct of the study; has received research support from NICHD-NIH; earns royalties from UpToDate; and has served as a consultant for AbbVie, Myovant Sciences, Bayer, and Merck. The authors report no other potential conflicts of interest for this work.

\section{References}

1. Burton-Jeangros C, Cullati S, Sacker A, Blane D. Introduction. In: Burton-Jeangros C, Cullati S, Sacker A, Blane D, editors. A Life Course Perspective on Health Trajectories and Transitions. Cham (CH); 2015:1-18. Springer International Publishing.

2. Ros S, Puig L, Carrascosa JM. Cumulative life course impairment: the imprint of psoriasis on the patient's life. Actas Dermosifiliogr. 2014;105:128-134. doi:10.1016/j.ad.2013.02.009

3. Bhatti Z, Salek M, Finlay A. Chronic diseases influence major life changing decisions: a new domain in quality of life research. $J R$ Soc Med. 2011;104(6):241-250. doi:10.1258/jrsm.2011.110010

4. Uhlenberg P, Mueller M, eds. Family Context and Individual Well-Being. Patterns and Mechanisms in Life Course Perspective. New York: Kluwer/Plenum; 2003.

5. Kimball AB, Gieler U, Linder D, Sampogna F, Warren RB, Augustin M. Psoriasis: is the impairment to a patient's life cumulative? J Eur Acad Dermatol Venereol. 2010;24:989-1004.

6. Kaye EC, Brinkman TM, Baker JN. Development of depression in survivors of childhood and adolescent cancer: a multi-level life course conceptual framework. Support Care Cancer. 2017;25 (6):2009-2017. doi:10.1007/s00520-017-3659-y

7. Kwon E, Park S. Heterogeneous trajectories of physical and mental health in late middle age: importance of life-course socioeconomic positions. Int J Environ Res Public Health. 2017;14 (6):582. doi:10.3390/ijerph14060582

8. Hellman KM, Roth GE, Dillane KE, et al. Dysmenorrhea subtypes exhibit differential quantitative sensory assessment profiles. Pain. 2020;161(6):1227-1236. doi:10.1097/j.pain.0000000000001826

9. Cagnacci A, Della Vecchia E, Xholli A. Chronic pelvic pain improvement: impact on quality of life and mood. Gynecol Endocrinol. 2019;35:502-505.

10. Tripoli TM, Sato H, Sartori MG, de Araujo FF, Girao MJBC, Schor E. Evaluation of quality of life and sexual satisfaction in women suffering from chronic pelvic pain with or without endometriosis. J Sex Med. 2011;8(2):497-503. doi:10.1111/j.1743-6109.2010.01976.x

11. Nnoaham KE, Hummelshoj L, Webster P, et al. Impact of endometriosis on quality of life and work productivity: a multicenter study across ten countries. Fertil Steril. 2011;96(2):366-73 e8. doi:10.1016/j.fertnstert.2011.05.090

12. Hooker AB, van Moorst BR, van Haarst EP, van Ootegehem NA, van Dijken DK, Heres MH. Chronic pelvic pain: evaluation of the epidemiology, baseline demographics, and clinical variables via a prospective and multidisciplinary approach. Clin Exp Obstet Gynecol. 2013;40:492-498.
13. Oladosu FA, Hellman KM, Ham PJ, et al. Persistent autonomic dysfunction and bladder sensitivity in primary dysmenorrhea. Sci Rep. 2019;9(1):2194. doi:10.1038/s41598-019-38545-3

14. Zondervan KT, Yudkin PL, Vessey MP, et al. The community prevalence of chronic pelvic pain in women and associated illness behaviour. Br J Gen Pract. 2001;51:541-547.

15. Stones RW, Price C. Health services for women with chronic pelvic pain. J R Soc Med. 2002;95(11):531-535. doi:10.1177/ 014107680209501102

16. Lagana AS, La Rosa VL, Rapisarda AMC, et al. Anxiety and depression in patients with endometriosis: impact and management challenges. Int $J$ Womens Health. 2017;9:323-330. doi:10.2147/IJWH.S119729

17. Vitale SG, Capriglione S, Peterlunger I, et al. The role of oxidative stress and membrane transport systems during endometriosis: a fresh look at a busy corner. Oxid Med Cell Longev. 2018;2018:7924021. doi:10.1155/2018/7924021

18. Sapkota Y, Steinthorsdottir V, Morris AP, et al. Meta-analysis identifies five novel loci associated with endometriosis highlighting key genes involved in hormone metabolism. Nat Commun. 2017;8(1):15539. doi:10.1038/ncomms 15539

19. Laganà AS, Vitale SG, Salmeri FM, et al. Unus pro omnibus, omnes pro uno: a novel, evidence-based, unifying theory for the pathogenesis of endometriosis. Med Hypotheses. 2017;103:10-20. doi:10.1016/j.mehy.2017.03.032

20. McKinnon B, Bersinger NA, Wotzkow C, Mueller MD. Endometriosis-associated nerve fibers, peritoneal fluid cytokine concentrations, and pain in endometriotic lesions from different locations. Fertil Steril. 2012;97(2):373-380. doi:10.1016/j. fertnstert.2011.11.011

21. Giamberardino MA, Costantini R, Affaitati G, et al. Viscerovisceral hyperalgesia: characterization in different clinical models. Pain. 2010;151(2):307-322. doi:10.1016/j. pain.2010.06.023

22. Vincent K, Warnaby C, Stagg CJ, Moore J, Kennedy S, Tracey I. Dysmenorrhoea is associated with central changes in otherwise healthy women. Pain. 2011;152(9):1966-1975. doi:10.1016/j. pain.2011.03.029

23. As-Sanie S, Harris RE, Napadow V, et al. Changes in regional gray matter volume in women with chronic pelvic pain: a voxel-based morphometry study. Pain. 2012;153(5):1006-1014. doi:10.1016/j.pain.2012.01.032

24. As-Sanie S, Harris RE, Harte SE, Tu FF, Neshewat G, Clauw DJ. Increased pressure pain sensitivity in women with chronic pelvic pain. Obstet Gynecol. 2013;122(5):1047-1055. doi:10.1097/ AOG.0b013e3182a7e1f5

25. Agarwal SK, Foster WG, Groessl EJ. Rethinking endometriosis care: applying the chronic care model via a multidisciplinary program for the care of women with endometriosis. Int $J$ Womens Health. 2019;11:405-410. doi:10.2147/IJWH. S207373

26. Agarwal SK, Chapron C, Giudice LC, et al. Clinical diagnosis of endometriosis: a call to action. Am J Obstet Gynecol. 2019;220(4):354 e1- e12. doi:10.1016/j.ajog.2018.12.039

27. Eskenazi B, Warner ML. Epidemiology of endometriosis. Obstet Gynecol Clin North Am. 1997;24(2):235-258. doi:10.1016/ S0889-8545(05)70302-8

28. Soliman AM, Surrey E, Bonafede M, Nelson JK, CastelliHaley J. Real-world evaluation of direct and indirect economic burden among endometriosis patients in the United States. Adv Ther. 2018;35(3):408-423. doi:10.1007/s12325-018-0667-3

29. Ballard K, Lowton K, Wright J. What's the delay? A qualitative study of women's experiences of reaching a diagnosis of endometriosis. Fertil Steril. 2006;86(5):1296-1301. doi:10.1016/j. fertnstert.2006.04.054 
30. Lamvu G, Antunez-Flores O, Orady M, Schneider B. Path to diagnosis and women's perspectives on the impact of endometriosis pain. J Endometr Pelvic Pain Disord. 2020;12(1):16-25. doi: $10.1177 / 2284026520903214$

31. Hallstam A, Stalnacke BM, Svensen C, Lofgren M. Living with painful endometriosis - a struggle for coherence. A qualitative study. Sex Reprod Healthc. 2018;17:97-102. doi:10.1016/j. srhc.2018.06.002

32. Lovkvist L, Bostrom P, Edlund M, Olovsson M. Age-related differences in quality of life in Swedish women with endometriosis. J Womens Health (Larchmt). 2016;25(6):646-653. doi:10.1089/ jwh.2015.5403

33. Culley L, Law C, Hudson N, et al. The social and psychological impact of endometriosis on women's lives: a critical narrative review. Hum Reprod Update. 2013;19(6):625-639. doi:10.1093/ humupd/dmt027

34. Moradi M, Parker M, Sneddon A, Lopez V, Ellwood D. Impact of endometriosis on women's lives: a qualitative study. BMC Womens Health. 2014;14(1):123. doi:10.1186/1472-6874-14-123

35. Oehmke F, Weyand J, Hackethal A, Konrad L, Omwandho C, Tinneberg H-R. Impact of endometriosis on quality of life: a pilot study. Gynecol Endocrinol. 2009;25(11):722-725. doi:10.3109/ 09513590903159607

36. La Rosa VL, De Franciscis P, Barra F, et al. Sexuality in women with endometriosis: a critical narrative review. Minerva Med. 2020;111:79-89.

37. La Rosa VL, De Franciscis P, Barra F, et al. Quality of life in women with endometriosis: a narrative overview. Minerva Med. 2020;111:68-78.

38. Della Corte L, Di Filippo C, Gabrielli O, et al. The burden of endometriosis on women's lifespan: a narrative overview on quality of life and psychosocial wellbeing. Int $J$ Environ Res Public Health. 2020;17(13):4683. doi:10.3390/ijerph17134683

39. Cavaggioni G, Lia C, Resta S, et al. Are mood and anxiety disorders and alexithymia associated with endometriosis? A preliminary study. Biomed Res Int. 2014;2014:786830. doi: $10.1155 / 2014 / 786830$

40. Souza CA, Oliveira LM, Scheffel C, et al. Quality of life associated to chronic pelvic pain is independent of endometriosis diagnosis-a cross-sectional survey. Health Qual Life Outcomes. 2011;9:41. doi:10.1186/1477-7525-9-41

41. Sperschneider ML, Hengartner MP, Kohl-Schwartz A, et al. Does endometriosis affect professional life? A matched case-control study in Switzerland, Germany and Austria. BMJ Open. 2019;9 (1):e019570. doi:10.1136/bmjopen-2017-019570

42. Galea S, Tracy M. Participation rates in epidemiologic studies. Ann Epidemiol. 2007;17:643-653. doi:10.1016/j.annepidem.2007.03.013

43. Morton LM, Cahill J, Hartge P. Reporting participation in epidemiologic studies: a survey of practice. Am J Epidemiol. 2006;163 (3):197-203. doi:10.1093/aje/kwj036

44. Facchin F, Barbara G, Dridi D, et al. Mental health in women with endometriosis: searching for predictors of psychological distress. Hum Reprod. 2017;32(9):1855-1861. doi:10.1093/humrep/dex249

45. Hudson N, Culley L, Law C, Mitchell H, Denny E, RaineFenning N. 'We needed to change the mission statement of the marriage': biographical disruptions, appraisals and revisions among couples living with endometriosis. Sociol Health Illn. 2016;38(5):721-735. doi:10.1111/1467-9566.12392

46. Chapron C, Lafay-Pillet M-C, Monceau E, et al. Questioning patients about their adolescent history can identify markers associated with deep infiltrating endometriosis. Fertil Steril. 2011;95 (3):877-881. doi:10.1016/j.fertnstert.2010.10.027

47. DiVasta AD, Vitonis AF, Laufer MR, Missmer SA. Spectrum of symptoms in women diagnosed with endometriosis during adolescence vs adulthood. Am J Obstet Gynecol. 2018;218(3):324 e1e11. doi:10.1016/j.ajog.2017.12.007
48. Soderman L, Edlund M, Marions L. Prevalence and impact of dysmenorrhea in Swedish adolescents. Acta Obstet Gynecol Scand. 2019;98:215-221. doi:10.1111/aogs.13480

49. Murray CB, Groenewald CB, de la Vega R, Palermo TM. Longterm impact of adolescent chronic pain on young adult educational, vocational, and social outcomes. Pain. 2020;161:439-445.

50. Kashikar-Zuck S, Cunningham N, Peugh J, et al. Long-term outcomes of adolescents with juvenile-onset fibromyalgia into adulthood and impact of depressive symptoms on functioning over time. Pain. 2019;160:433-441.

51. Fourquet J, Baez L, Figueroa M, Iriarte RI, Flores I. Quantification of the impact of endometriosis symptoms on health-related quality of life and work productivity. Fertil Steril. 2011;96:107-112. doi:10.1016/j.fertnstert.2011.04.095

52. Fourquet J, Gao X, Zavala D, et al. Patients' report on how endometriosis affects health, work, and daily life. Fertil Steril. 2010;93:2424-2428. doi:10.1016/j.fertnstert.2009.09.017

53. Hansen KE, Kesmodel US, Baldursson EB, Schultz R, Forman A. The influence of endometriosis-related symptoms on work life and work ability: a study of Danish endometriosis patients in employment. Eur J Obstet Gynecol Reprod Biol. 2013;169 (2):331-339. doi:10.1016/j.ejogrb.2013.03.008

54. Facchin F, Buggio L, Ottolini F, Barbara G, Saita E, Vercellini P. Preliminary insights on the relation between endometriosis, pelvic pain, and employment. Gynecol Obstet Invest. 2019;84:190-195. doi:10.1159/000494254

55. Soliman AM, Coyne KS, Gries KS, Castelli-Haley J, Snabes MC, Surrey ES. The effect of endometriosis symptoms on absenteeism and presenteeism in the workplace and at home. J Manag Care Spec Pharm. 2017;23:745-754.

56. Estes SJ, Soliman AM, Yang H, Wang J. A longitudinal assessment of the impact of endometriosis on patients' salaries. Fertil Steril. 2019;112(3):e321. doi:10.1016/j.fertnstert.2019.07.930

57. Abd El-Kader AI, Gonied AS, Lotfy Mohamed M, Lotfy Mohamed S. Impact of endometriosis-related adhesions on quality of life among infertile women. Int J Fertil Steril. 2019;13:72-76.

58. Levy AR, Osenenko KM, Lozano-Ortega G, et al. Economic burden of surgically confirmed endometriosis in Canada. J Obstet Gynaecol Can. 2011;33(8):830-837. doi:10.1016/S1701-2163(16)34986-6

59. Soliman AM, Taylor HS, Bonafede M, Nelson JK, Castelli-Haley J. Incremental direct and indirect cost burden attributed to endometriosis surgeries in the United States. Fertil Steril. 2017;107 (5):1181-90 e2. doi:10.1016/j.fertnstert.2017.03.020

60. Pizzi LT, Carter CT, Howell JB, Vallow SM, Crawford AG, Frank ED. Work loss, healthcare utilization, and costs among US employees with chronic pain. Dis Manag Health Out. 2005;13(3):201-208. doi:10.2165/00115677-200513030-00005

61. Ramin-Wright A, Schwartz ASK, Geraedts K, et al. Fatigue a symptom in endometriosis. Hum Reprod. 2018;33:1459-1465. doi:10.1093/humrep/dey115

62. Roomaney R, Kagee A. Salient aspects of quality of life among women diagnosed with endometriosis: a qualitative study. J Health Psychol. 2018;23(7):905-916. doi:10.1177/1359105316643069

63. Rush G, Misajon R. Examining subjective wellbeing and health-related quality of life in women with endometriosis. Health Care Women Int. 2018;39:303-321. doi:10.1080/ 07399332.2017.1397671

64. Soliman AM, Coyne KS, Zaiser E, Castelli-Haley J, Fuldeore MJ. The burden of endometriosis symptoms on health-related quality of life in women in the United States: a cross-sectional study. J Psychosom Obstet Gynaecol. 2017;38:238-248. doi:10.1080/ 0167482X.2017.1289512

65. Kundu S, Wildgrube J, Schippert C, Hillemanns P, Brandes I. Supporting and inhibiting factors when coping with endometriosis from the patients' perspective. Geburtshilfe Frauenheilkd. 2015;75:462-469. doi:10.1055/s-0035-1546052 
66. Forgeron PA, King S, Stinson JN, McGrath PJ, MacDonald AJ, Chambers CT. Social functioning and peer relationships in children and adolescents with chronic pain: a systematic review. Pain Res Manag. 2010;15:27-41. doi:10.1155/2010/820407

67. Kashikar-Zuck S, Lynch AM, Graham TB, Swain NF, Mullen SM, Noll RB. Social functioning and peer relationships of adolescents with juvenile fibromyalgia syndrome. Arthritis Rheum. 2007;57(3):474-480. doi:10.1002/art.22615

68. Prescott J, Farland LV, Tobias DK, et al. A prospective cohort study of endometriosis and subsequent risk of infertility. Hum Reprod. 2016;31(7):1475-1482. doi:10.1093/humrep/dew085

69. Coffey S, Bano G, Mason HD. Health-related quality of life in women with polycystic ovary syndrome: a comparison with the general population using the Polycystic Ovary Syndrome Questionnaire (PCOSQ) and the short form-36 (SF-36). Gynecol Endocrinol. 2006;22(2):80-86. doi:10.1080/09513590600604541

70. Ameratunga D, Flemming T, Angstetra D, Ng S-K, Sneddon A. Exploring the impact of endometriosis on partners. $J$ Obstet Gynaecol Res. 2017;43(6):1048-1053. doi:10.1111/jog.13325

71. Cozzolino M, Magro-Malosso ER, Tofani L, Coccia ME. Evaluation of sexual function in women with deep infiltrating endometriosis. Sex Reprod Healthc. 2018;16:6-9. doi:10.1016/j. srhc.2017.12.005

72. De Graaff AA, Van Lankveld J, Smits LJ, Van Beek JJ, Dunselman GA. Dyspareunia and depressive symptoms are associated with impaired sexual functioning in women with endometriosis, whereas sexual functioning in their male partners is not affected. Hum Reprod. 2016;31(11):2577-2586. doi:10.1093/ humrep/dew215

73. Di Donato N, Montanari G, Benfenati A, et al. Sexual function in women undergoing surgery for deep infiltrating endometriosis: a comparison with healthy women. J Fam Plann Reprod Health Care. 2015;41(4):278-283. doi:10.1136/jfprhc-2014-100993

74. Fritzer N, Haas D, Oppelt P, et al. More than just bad sex: sexual dysfunction and distress in patients with endometriosis. Eur J Obstet Gynecol Reprod Biol. 2013;169:392-396.

75. Hammerli S, Kohl Schwartz AS, Geraedts K, et al. Does endometriosis affect sexual activity and satisfaction of the man partner? A comparison of partners from women diagnosed with endometriosis and controls. J Sex Med. 2018;15(6):853-865. doi:10.1016/j.jsxm.2018.03.087

76. Lima RV, Pereira AMG, Beraldo FB, Gazzo C, Martins JA, Lopes RGC. Female sexual function in women with suspected deep infiltrating endometriosis. Rev Bras Ginecol Obstet. 2018;40:115-120. doi:10.1055/s-0038-1639593

77. Montanari G, Di Donato N, Benfenati A, et al. Women with deep infiltrating endometriosis: sexual satisfaction, desire, orgasm, and pelvic problem interference with sex. J Sex Med. 2013;10 (6):1559-1566. doi:10.1111/jsm.12133

78. Vercellini P, Somigliana E, Buggio L, Barbara G, Frattaruolo MP, Fedele L. "I can't get no satisfaction": deep dyspareunia and sexual functioning in women with rectovaginal endometriosis. Fertil Steril. 2012;98(6):1503-11 e1. doi:10.1016/j. fertnstert.2012.07.1129

79. Zarbo C, Brugnera A, Compare A, et al. Negative metacognitive beliefs predict sexual distress over and above pain in women with endometriosis. Arch Womens Ment Health. 2019;22(5):575-582. doi:10.1007/s00737-018-0928-9

80. Geisser ME, Cano A, Leonard MT. Factors associated with marital satisfaction and mood among spouses of persons with chronic back pain. $J$ Pain. 2005;6(8):518-525. doi:10.1016/j. jpain.2005.03.004

81. Leonard MT, Cano A. Pain affects spouses too: personal experience with pain and catastrophizing as correlates of spouse distress. Pain. 2006;126(1):139-146. doi:10.1016/j.pain.2006.06.022
82. Chauvet P, Guiguet-Auclair C, Comptour A, et al. Feelings and expectations in endometriosis: analysis of open comments from a cohort of endometriosis patients. J Gynecol Obstet Hum Reprod. 2018;47:281-287. doi:10.1016/j.jogoh.2018.05.010

83. Gonzalez-Echevarria AM, Rosario E, Acevedo S, Flores I. Impact of coping strategies on quality of life of adolescents and young women with endometriosis. J Psychosom Obstet Gynaecol. 2019;40:138-145. doi:10.1080/0167482X.2018.1450384

84. Surrey ES, Soliman AM, Johnson SJ, Davis M, Castelli-Haley J, Snabes MC. Risk of developing comorbidities among women with endometriosis: a retrospective matched cohort study. $J$ Womens Health (Larchmt). 2018;27(9):1114-1123. doi:10.1089/jwh.2017.6432

85. Friedl F, Riedl D, Fessler S, et al. Impact of endometriosis on quality of life, anxiety, and depression: an Austrian perspective. Arch Gynecol Obstet. 2015;292(6):1393-1399. doi:10.1007/ s00404-015-3789-8

86. Smorgick N, Marsh CA, As-Sanie S, Smith YR, Quint EH. Prevalence of pain syndromes, mood conditions, and asthma in adolescents and young women with endometriosis. J Pediatr Adolesc Gynecol. 2013;26:171-175. doi:10.1016/j. jpag.2012.12.006

87. Vannuccini S, Lazzeri L, Orlandini C, et al. Mental health, pain symptoms and systemic comorbidities in women with endometriosis: a cross-sectional study. J Psychosom Obstet Gynaecol. 2018;39:315-320. doi:10.1080/0167482X.2017.1386171

88. Pompili M, Serafini G, Di Cosimo D, et al. Psychiatric comorbidity and suicide risk in patients with chronic migraine. Neuropsychiatr Dis Treat. 2010;6:81. doi:10.2147/NDT.S8467

89. Tunks ER, Crook J, Weir R. Epidemiology of chronic pain with psychological comorbidity: prevalence, risk, course, and prognosis. Can J Psychiatry. 2008;53(4):224-234. doi:10.1177/ 070674370805300403

90. Gallagher JS, DiVasta AD, Vitonis AF, Sarda V, Laufer MR, Missmer SA. The impact of endometriosis on quality of life in adolescents. J Adolesc Health. 2018;63:766-772. doi:10.1016/j. jadohealth.2018.06.027

91. Kiykac Altinbas S, Bayoglu Tekin Y, Dilbaz B, Dilbaz S. Evaluation of quality of life in fertile Turkish women with severe endometriosis. J Obstet Gynaecol. 2015;35(1):49-52. doi:10.3109/01443615.2014.930110

92. Marki G, Bokor A, Rigo J, Rigo A. Physical pain and emotion regulation as the main predictive factors of health-related quality of life in women living with endometriosis. Hum Reprod. 2017;32 (7):1432-1438. doi:10.1093/humrep/dex091

93. Kjaer TK, Johansen C, Ibfelt E, et al. Impact of symptom burden on health related quality of life of cancer survivors in a Danish cancer rehabilitation program: a longitudinal study. Acta Oncol. 2011;50(2):223-232. doi:10.3109/0284186X.2010.530689

94. Rzońca E, Bień A, Wdowiak A, Szymański R, Iwanowicz-Palus G. Determinants of quality of life and satisfaction with life in women with polycystic ovary syndrome. Int J Environ Res Public Health. 2018;15(2):376. doi:10.3390/ijerph15020376

95. Jenkins CD. Assessment of outcomes of health intervention. Soc Sci Med. 1992;35(4):367-375. doi:10.1016/0277-9536(92)90329$\mathrm{O}$

96. Megari K. Quality of life in chronic disease patients. Health Psychol Res. 2013;1(3):27. doi:10.4081/hpr.2013.932

97. Leone Roberti Maggiore U, Bizzarri N, Scala C, et al. Symptomatic endometriosis of the posterior cul-de-sac is associated with impaired sleep quality, excessive daytime sleepiness and insomnia: a case-control study. Eur J Obstet Gynecol Reprod Biol. 2017;209:39-43. doi:10.1016/j.ejogrb.2015.11.026

98. Lazzeri L, Orlandini C, Vannuccini S, et al. Endometriosis and perceived stress: impact of surgical and medical treatment. Gynecol Obstet Invest. 2015;79:229-233. doi:10.1159/000368776 
99. Petrelluzzi KF, Garcia MC, Petta CA, Grassi-Kassisse DM, SpadariBratfisch RC. Salivary cortisol concentrations, stress and quality of life in women with endometriosis and chronic pelvic pain. Stress. 2008;11:390-397. doi:10.1080/10253890701840610

100. Quinones M, Urrutia R, Torres-Reveron A, Vincent K, Flores I. Anxiety, coping skills and hypothalamus-pituitary-adrenal (HPA) axis in patients with endometriosis. $J$ Reprod Biol Health. 2015;3.

101. van Aken M, Oosterman J, van Rijn T, et al. Hair cortisol and the relationship with chronic pain and quality of life in endometriosis patients. Psychoneuroendocrinology. 2018;89:216-222. doi:10.10 16/j.psyneuen.2018.01.001

102. Evans SF, Brooks TA, Esterman AJ, Hull ML, Rolan PE. The comorbidities of dysmenorrhea: a clinical survey comparing symptom profile in women with and without endometriosis. J Pain Res. 2018;11:3181-3194. doi:10.2147/JPR.S179409
103. Zarbo C, Brugnera A, Compare A, et al. Perfectionistic traits and importance given to parenthood are associated with infertility-related quality of life in a sample of infertile women with and without endometriosis. Sex Reprod Healthc. 2018;17:86-90. doi:10.1016/j.srhc.2018.07.008

104. Culley L, Law C, Hudson N, Mitchell H, Denny E, RaineFenning N. A qualitative study of the impact of endometriosis on male partners. Hum Reprod. 2017;32(8):1667-1673. doi:10.1093/humrep/dex221

\section{Publish your work in this journal}

The International Journal of General Medicine is an international, peer-reviewed open-access journal that focuses on general and internal medicine, pathogenesis, epidemiology, diagnosis, monitoring and treatment protocols. The journal is characterized by the rapid reporting of reviews, original research and clinical studies across all disease areas. The manuscript management system is completely online and includes a very quick and fair peer-review system, which is all easy to use. Visit http://www.dovepress.com/ testimonials.php to read real quotes from published authors.

Submit your manuscript here: https://www.dovepress.com/international-journal-of-general-medicine-journal 